\title{
A los niños, niñas, sus padres y familiares
}

\section{Martín Álvarez}

Pediatra de Atención Primaria, Madrid.

\section{Sr. Director de la Revista Pediatría de Atención Primaria:}

Madrid, 2 de enero de 2013. Ha llegado el momento de mi jubilación como pediatra del Servicio Madrileño de Salud y ante la imposibilidad de despedirme personalmente de cada uno de los niños y niñas, sus padres y familiares que durante los últimos años han acudido a la consulta de Pediatría del Centro de Salud Caramuel, no quiero dejar de manifestarles mi agradecimiento por todo lo que me han aportado como persona y como pediatra en estos mis últimos años de trabajo, tanto en la situaciones de enfermedad como en la prevención y promoción de la salud de todos los niños y niñas. Todo esto no hubiera sido posible sin la colaboración de todos, niños, niñas, padres, enfermeras, administrativos, celadores y personal de limpieza del centro de salud. Son los momentos actuales difíciles para todos, usuarios niños y adultos y trabajadores de un servicio público como es el Centro de Salud Caramuel, pero estoy seguro de que el trabajo y la participación de todos, usuarios y trabajadores, logrará mantener y mejorar lo conseguido por el esfuerzo de nuestros mayores y de los que siguen en activo y que las generaciones venideras deben conocer y cuidar como patrimonio de todos. 